\title{
Pengaruh Pelatihan Pelayanan Kefarmasian Terhadap Pengetahuan Pengelola Obat di Puskesmas Kabupaten Ogan Komering Ilir
}

\author{
The Effect of Pharmaceutical Service Training on Drug Manager Knowledge at Public Health Center of \\ Ogan Komering Ilir District
}

Hafizh Amrullah ${ }^{1 *}$, Satibi ${ }^{2}$, Achmad Fudholi $^{2}$

1. Fakultas Magister Manajemen Farmasi, Universitas Gadjah Mada

2. Fakultas Farmasi, Universitas Gadjah Mada

Submitted: 15-10-2019 Revised: 25-03-2020

Korespondensi : Hafizh Amrullah : Email : roelly.1983@gmail.com

Accepted: 26-03-2020

\begin{abstract}
ABSTRAK
Meningkatnya jumlah kunjungan pasien puskesmas di era JKN menuntut kesiapan petugas puskesmas terutama tenaga kefarmasian dalam melayani masyarakat. Pengetahuan menjadi kebutuhan utama dalam menjalin kolaborasi dengan profesional kesehatan lainnya agar kualitas pelayanan kesehatan meningkat. Masih lemahnya pengetahuan menuntut adanya pelatihan khusus bagi tenaga kefarmasian dalam meningkatkan kompetensinya dalam pengelolaan obat dan pelayanan farmasi klinik. Penelitian ini bertujuan untuk mengetahui pengaruh pelatihan pelayanan kefarmasian terhadap pengetahuan pengelola obat puskesmas di kabupaten Ogan Komering Ilir. Penelitian ini merupakan penelitian quasi-experimental design dengan pendekatan analisis pre dan post pada kelompok intervensi serta menggunakan kelompok kontrol sebagai pembanding. Subyek pada penelitian adalah pengelola obat di puskesmas kabupaten Ogan Komering Ilir yang memenuhi kriteria. Intervensi dilakukan dengan pemberian pelatihan terhadap pengelola obat dan pemberian buku pedoman pelayanan kefarmasian. Materi pelatihan yang diberikan berdasarkan kurikulum pelatihan pelayanan kefarmasian yang disusun oleh Kementerian Kesehatan RI. Instrumen lain yang digunakan adalah kuesioner yang telah divalidasi untuk mengukur skor pengetahuan pengelola obat sebelum dan sesudah dilakukan pelatihan. Sebanyak 13 pengelola obat berpartisipasi dalam penelitian ini. Pada saat setelah pelatihan, skor pengetahuan pengelola obat pada kelompok intervensi mengalami peningkatan dari 9,83 $\pm 2,401$ menjadi 12,67 $\pm 2,338$ dengan nilai $p=0,013$. Mayoritas pengelola obat kelompok intervensi mengalami peningkatan pengetahuan baik dari aspek pengelolaan obat maupun aspek pelayanan farmasi klinik. Studi ini menyimpulkan bahwa pelatihan terhadap pengelola obat memberikan pengaruh dalam meningkatkan pengetahuan aspek pengelolaan obat dan pelayanan farmasi klinik.

Kata kunci: pelatihan; pengetahuan; pengelola obat; pelayanan kefarmasian; puskesmas
\end{abstract}

\section{ABSTRACT}

The increasing number of patients admited to primary healthcare (PHC) in the JKN era demands the readiness of PHC's staff, especially pharmaceutical staff, to serve the community. Knowledge is a major necessity in collaborating with other health profesional to improve the quality of health services. Pharmaceutical staff who lack knowledge needs special training to improve their competences in drug management and clinical pharmacy services. This study aims to determine the effect of pharmacy service training on the knowledge of drug manager in PHC's of Ogan Komering Ilir district. This research is a quasiexperimental design research with pre and post analysis approach in the intervention group and using the control group as a comparison. Subjects in the study were drug managers in the PHC's of Ogan Komering Ilir district that met the criteria. The intervention was carried out by providing training to drug manager and providing pharmacy service manuals. The training material provided was based on the Pharmaceutical Services Training Curriculum compiled by Ministry of Health. Another instrument used was a validated questionnaire to measure the knowledge score of drug managers before and after training. A total of 13 drug managers participated in this study. After the training, the knowledge score of drug manager in the intervention group increased from $9.83 \pm 2.401$ to $12.67 \pm 2.333$ with value of $p=$ 0.013 . The majority of intervention group drug managers experienced an increase in knowledge both from the aspect of drug management and clinical pharmacy service aspects. This study concludes that training 
of drug managers has an effect on increasing knowledge of aspects of drug management and clinical pharmacy services.

Keywords: training; knowledge; drug manager; pharmaceutical services; public healthcare

\section{PENDAHULUAN}

Di era Jaminan Kesehatan Nasional (JKN) terjadi peningkatan jumlah kunjungan pasien ke Fasilitas Kesehatan Tingkat Pertama (FKTP) termasuk puskesmas sehingga dibutuhkan sumber daya kesehatan yang memadai. Ketersediaan sumber daya manusia dalam pelaksanaan pelayanan kesehatan memegang peranan penting pada saat ini. Dengan meningkatnya kunjungan maka diperlukan juga kesiapan petugas atau sumber daya manusia dalam melayani masyarakat. ${ }^{1}$ Kualitas pelayanan kesehatan erat kaitannya dengan tingkat pengetahuan petugas. Hubungan antara pengetahuan petugas terhadap kualitas pelayanan kesehatan diungkapkan pada studi Aryani, dkk di mana semakin baik tingkat pengetahuan pengelola obat maka semakin baik pula pengelolaan obatnya di puskesmas ${ }^{2}$. Srikanth,dkk. mempunyai pandangan bahwa pengetahuan dan keterampilan sangat penting dalam memberikan layanan profesional yang bermakna dan bermanfaat. ${ }^{3}$

Kualitas sumber daya manusia dapat ditingkatkan dengan mengikuti berbagai pelatihan yang akan meningkatkan kompetensinya sebagai tenaga kesehatan. Hajj,dkk. ${ }^{4}$ dalam penelitiannya mengungkapkan bahwa lemahnya pengetahuan disebabkan karena kurangnya pelatihan yang diikuti oleh apoteker, sehingga pada studi Alrabiah,dkk. ${ }^{5}$ memberikan solusi akan adanya pelatihan khusus untuk farmasis komunitas untuk mengatasi kelemahankelemahan tersebut. Pelatihan dapat secara langsung meningkatkan kualitas hidup pasien dengan mencegah terjadinya medication error seperti yang diungkapkan pada studi Mussina, $\mathrm{dkk}^{6}$ di mana intervensi berupa program pelatihan farmakoterapi dapat menurunkan kejadian interaksi obat. Penelitian Liekens,dkk. ${ }^{7}$ juga memberikan gambaran pentingnya pelatihan bagi farmasis agar dapat meningkatkan kualitas perawatan pasien gangguan kejiwaan yang mengkonsumsi obat-obatan antidepresi. Kewajiban pelatihan bagi tenaga profesional di puskesmas ditegaskan pada penelitian Sambala,dkk. ${ }^{8}$ bahwa pelatihan tenaga kesehatan dapat mempengaruhi aksesibilitas obat ke masyarakat.

Filosofi pelayanan kefarmasian (pharmaceutical care) yang berorientasi pada pasien telah diterapkan di banyak negara. Pengaruh positif dari pelayanan kefarmasian berorientasi pada pasien telah ditunjukkan pada beberapa penelitian. ${ }^{9-11}$ Implementasi pelayanan kefarmasian (pharmaceutical care) yang baik dilakukan di sebagian besar negara maju. Meskipun membutuhkan biaya yang besar, namun implementasi tersebut telah berhasil meningkatkan pelayanan kefarmasian lebih baik, seperti: edukasi pasien, konseling, memberikan pertimbangan farmakoterapi, pertimbangan farmakoekonomi, pemantauan kondisi pasien, penyelesaian masalah yang berkaitan dengan obat, beserta pendokumentasiannya. ${ }^{12-14}$ Lain halnya di negara berkembang, pelayanan kefarmasian kurang diperhatikan, terutama pada peran tenaga kefarmasian yang bekerja di puskesmas. ${ }^{15}$ Hal mendasar yang menyebabkan kondisi tersebut adalah kurangnya pendidikan dan pelatihan kefarmasian yang memadai. ${ }^{16,17}$ Pengetahuan menjadi kunci utama dalam pemecahan masalah-masalah tersebut. Kurangnya pengetahuan menjadi salah satu hambatan dalam implementasi pelayanan kefarmasian di puskesmas yang baik. Tenaga kefarmasian merasa kurang mampu memberikan informasi obat kepada tenaga kesehatan lainnya di puskesmas akibat lemahnya pengetahuan. ${ }^{18}$ Lemahnya aspek ketanggapan tenaga kefarmasian dalam memberikan pelayanan resep juga mengakibatkan rendahnya kepuasan pasien di puskesmas. ${ }^{19}$ Penelitian yang dilakukan oleh Pawar dan Pawar mengungkapkan bahwa pelatihan 
pelayanan kefarmasian dapat meningkatkan secara signifikan pengetahuan dan sikap farmasis. ${ }^{20}$

Indonesia sebagai negara berkembang, khususnya kabupaten Ogan Komering Ilir Provinsi Sumatera Selatan memiliki ketersediaan tenaga kefarmasian yang terbatas dan tidak merata. Selain itu, latar belakang pendidikan dan masa kerja pengelola obat yang berbeda mengakibatkan tingkat pengetahuan yang beragam. Belum ada penelitian yang mengungkapkan seberapa besar dampak pelatihan terhadap peningkatan pengetahuan apoteker dan tenaga teknis kefarmasian yang berpedoman pada kurikulum yang disusun oleh Kementerian Kesehatan RI. Penelitian ini bertujuan untuk mengetahui pengaruh pelatihan pelayanan kefarmasian terhadap pengetahuan pengelola obat puskesmas di kabupaten Ogan Komering Ilir.

\section{METODE}

\section{Desain Penelitian}

Penelitian ini merupakan penelitian quasi-experimental design dengan pendekatan analisis pre dan post serta menggunakan kelompok kontrol sebagai pembanding. Intervensi dilakukan dengan mengadakan pelatihan berupa workshop pelayanan kefarmasian puskesmas dan pemberian buku pedoman pelayanan kefarmasian. Penelitian ini dilaksanakan di Puskesmas yang ada di Kabupaten Ogan Komering Ilir Provinsi Sumatera Selatan pada bulan Juli-Agustus 2019.

\section{Sasaran dan subyek penelitian}

Populasi pada penelitian ini adalah seluruh pengelola obat puskesmas di Kabupaten Ogan Komering Ilir. Sampel pada penelitian ini adalah pengelola obat yang merupakan tenaga kefarmasian, bekerja di puskesmas Kabupaten Ogan Komering Ilir yang memenuhi kriteria. Kriteria inklusinya adalah pengelola obat adalah apoteker ataupun tenaga teknis kefarmasian yang sudah bekerja di puskesmas lebih dari 1 (satu) tahun. Kriteria eksklusinya adalah pengelola obat yang tidak bersedia menjadi subyek penelitian. Pemilihan subyek penelitian menggunakan metode non-propability sample secara purposive sampling yaitu teknik penentuan sampel dengan pertimbangan tertentu.

Pengelola obat sebagai responden dibagi menjadi dua kelompok, yaitu kelompok intervensi dan kelompok kontrol, di mana tiap kelompok harus dapat mempresentasikan puskesmas berdasarkan kategori jenis tenaga kefarmasian, kemampuan penyelenggaraan, karakteristik wilayah kerja, dan status akreditasinya sehingga kedua kelompok tersebut dapat dianggap homogen seperti digambarkan pada tabel I.

\section{Instrumen penelitian}

Intervensi dilakukan dengan instrumen pemberian pelatihan terhadap pengelola obat dan pemberian buku pedoman pelayanan kefarmasian. Pelatihan pelayanan kefarmasian dilakukan bertujuan agar peserta mampu melakukan pengelolaan obat dan pelayanan farmasi klinik di puskesmas. Pelatihan diikuti oleh tenaga kefarmasian yang termasuk pada puskesmas kelompok intervensi selama 1 (satu) hari. Materi pelatihan yang diberikan berdasarkan Kurikulum Pelatihan Pelayanan Kefarmasian yang disusun oleh Kementerian Kesehatan $\mathrm{RI}^{21}$ terdiri dari standar pengelolaan obat dan pelayanan farmasi klinik. Materi standar pengelolaan obat dibawakan oleh pemateri dalam waktu 4 jam pelajaran dan materi pelayanan farmasi klinik dibawakan dalam waktu 3 jam pelajaran, di mana 1 jam pelajaran sama dengan 45 menit. Metode pelatihan yang dilakukan menggunakan ceramah tanya jawab, studi kasus, dan tugas baca buku yang dibagikan sebelum pelatihan. Media dan alat bantu yang digunakan adalah bahan tayangan (slide powerpoint), komputer, dan LCD proyektor. Pemateri pelatihan adalah tim pakar terdiri dari 3 orang berasal dari kalangan akademisi yang mempunyai keahlian khusus dalam manajemen pengelolaan obat di puskesmas. Buku pedoman pelayanan kefarmasian merupakan buku yang berisi penjabaran materi-materi yang berkaitan dengan standar pelayanan 
Tabel I. Distribusi Pengelompokan Puskesmas

\begin{tabular}{lcc}
\hline \multicolumn{1}{c}{ Kategori } & \multicolumn{2}{c}{ Puskesmas } \\
\cline { 2 - 3 } & $\begin{array}{c}\text { Kelompok Intervensi } \\
(\mathbf{n}=6)\end{array}$ & $\begin{array}{c}\text { Kelompok Kontrol } \\
(\mathbf{n}=7)\end{array}$ \\
\hline Tenaga Kefarmasian & 1 & 0 \\
$\quad$ Apoteker & 5 & 7 \\
$\quad$ Tenaga Teknis Kefarmasian & & 3 \\
Kemampuan Penyelenggaraan & 4 & 4 \\
$\quad$ Rawat Inap & 2 & 1 \\
$\quad$ Non Rawat Inap & & 5 \\
Karakteristik Wilayah Kerja & 1 & 1 \\
Perkotaan & 3 & 1 \\
Pedesaan & 2 & 0 \\
Terpencil/ Sangat Terpencil & & 6 \\
Status Akreditasi & 1 & 0 \\
Non Akreditasi & 0 & 0 \\
Dasar & 4 & \\
Madya & 1 & \\
Utama & 0 & \\
Paripurna & & \\
\hline
\end{tabular}

kefarmasian di puskesmas. Pembagian buku tersebut dilakukan agar responden dapat membaca kembali materi yang telah disampaikan pada pelatihan untuk diterapkan dalam pelaksanaan pelayanan kefarmasian di puskesmasnya masingmasing.

Instrumen berupa kuesioner pengetahuan terdiri dari 20 pertanyaan berkaitan dengan materi pelatihan yang diberikan kepada pengelola obat berupa pilihan ganda dengan satu jawaban yang benar yang terdiri dari 12 pertanyaan tentang aspek pengelolaan obat dan 8 pertanyaan tentang aspek pelayanan farmasi klinik. Jawaban yang benar diberi nilai $=1$ dan jawaban yang salah diberi nilai $=0$. Nilai maksimum kuesioner pengetahuan adalah 20 dan nilai minimumnya adalah 0 . Kuesioner ini diisi sebelum dan setelah dilakukan pelatihan untuk menilai peningkatan pengetahuan dan pemahaman pengelola obat. Pengelola obat puskesmas kelompok intervensi mengisi kuesioner sebelum dimulai pelatihan (pre-test) dan mengisi kembali kuesionernya (post-test) pada saat setelah pelatihan di hari yang sama. Pengelola obat puskesmas kelompok kontrol mengisi kuesioner (pre-test) pada saat sebelum pelatihan dan melakukan pengisian kuesioner lagi (post-test) 1 minggu setelahnya.

Uji validitas kuesioner pengetahuan pada penelitian ini dilakukan dengan validasi isi, di mana validitas isi menjadi sangat penting terutama dalam bidang pengukuran prestasi belajar atau pelatihan. Validitas tampang (face validity) yang menjadi titik awal evaluasi kualitas tes, terutama poin-poin pertanyaan yang disusun oleh tim peneliti. Selanjutnya untuk menilai kelayakan isi item pertanyaan sebagai penjabaran dari aspek yang akan dinilai, dilakukan professional judgement oleh 3 orang pakar dari Fakultas Farmasi Universitas Gadjah Mada Yogakarta yang memiliki keahlian dalam bidang manajemen obat. Hasil validasi adalah masukan-masukan dari para ahli, antara lain: kuesioner disusun dalam bentuk pilihan ganda, terdiri dari pertanyaan yang mencakup aspek pengetahuan mengenai pengelolaan obat dan pelayanan farmasi klinik, dan bentuk pertanyaannya lebih kepada contoh kasus yang berkaitan dengan rutinitas pengelola obat dalam melakukan pelayanan kefarmasian di puskesmas. 
Tabel II. Karakteristik Responden Penelitian

\begin{tabular}{lcc}
\hline \multicolumn{1}{c}{ Kategori } & Jumlah $(\mathbf{n}=\mathbf{1 3})$ & Persentase (\%) \\
\hline Jenis Kelamin & & \\
$\quad$ Laki-laki & 1 & 7,69 \\
$\quad$ Perempuan & 12 & 92,31 \\
Usia & & \\
$\quad<30$ tahun & 3 & 23,08 \\
$\quad 30-40$ tahun & 7 & 53,85 \\
$>40$ tahun & 3 & 23,08 \\
Pendidikan Terakhir & & \\
Apoteker & 1 & 7,69 \\
S1 Farmasi & 5 & 38,46 \\
D3 Farmasi & 7 & 53,85 \\
Masa Kerja & & \\
$\quad<3$ tahun & 2 & 15,38 \\
$3-7$ tahun & 3 & 23,08 \\
$>7$ tahun & 8 & 61,54 \\
\hline
\end{tabular}

\section{Analisis Data}

Karakteristik demografi pengelola obat dianalisis secara statistik deskriptif, berupa kuantitas dan persentase. Uji beda dilakukan terhadap skor kelompok intervensi dan kelompok kontrol menggunakan uji $\mathrm{T}$ tidak berpasangan dan uji $\mathrm{T}$ berpasangan dengan alat bantu analisis Statistical Product and Service Solution (SPSS) versi 23.

\section{Ethical clearance}

Penelitian ini disetujui oleh Komite Etika Penelitian Medis dan Kesehatan (MHREC) Fakultas Kedokteran Kesehatan Masyarakat dan Keperawatan Universitas Gadjah Mada - Rumah Sakit Umum Dr. Sardjito Yogyakarta dengan nomor sertifikat Ref: KE/FK/0924/EC/2019, tanggal 08 Agustus 2019.

\section{HASIL DAN PEMBAHASAN}

Sebanyak 13 pengelola obat dari 13 puskesmas di kabupaten Ogan Komering Ilir berpartisipasi pada penelitian ini. Gambaran terkait karakteristik pengelola obat sebagai responden diperoleh melalui analisis deskriptif disajikan pada tabel II. Sebagian besar responden dalam penelitian ini adalah perempuan sebanyak 12 responden $(92,31 \%)$. Hasil penelitian menunjukkan bahwa responden didominasi oleh usia produktif (30-40 tahun) sebesar 7 responden (53,85\%). Usia sangat erat kaitannya dengan produktivitas seseorang dalam bekerja. Dalam penelitian ini hanya ada 1 apoteker yang menjadi responden, lulusan S1 Farmasi sebanyak 5 responden, dan lulusan D3 menjadi responden terbanyak dengan 7 responden $(53,85 \%)$. Semakin tinggi tingkat pendidikan maka semakin besar pula keinginan untuk menambah pengetahuan dan ketrampilan. Sebagian besar responden telah memiliki pengalaman menjadi pengelola obat di puskesmas lebih dari 7 tahun sebanyak 8 responden (61,54\%), lama masa kerja berkaitan dengan pengetahuan yang dimiliki di bidang pengelolaan obat di puskesmas.

Penelitian ini dilakukan untuk mengetahui pengaruh pelatihan pelayanan kefarmasian terhadap pengetahuan pengelola obat di puskesmas. Studi ini juga untuk mengevaluasi kesiapan pengelola obat dalam melakukan pelayanan kefarmasian sesuai dengan standar pelayanan kefarmasian di puskesmas yang telah diatur dalam Permenkes No.74 Tahun 2016. Pelatihan dilakukan untuk memperkecil kesenjangan tingkat pengetahuan tenaga kefarmasian sebagai pengelola obat puskesmas yang 
Tabel III. Uji Beda Skor Pengetahuan Responden Sebelum dan Setelah Pelatihan

\begin{tabular}{lccc}
\hline \multicolumn{1}{c}{ Waktu Pengujian } & $\begin{array}{c}\text { Kelompok } \\
\text { Intervensi }\end{array}$ & Kelompok Kontrol & Nilai $\boldsymbol{p}^{* *}$ \\
\hline Sebelum Pelatihan* $^{*}$ & $9,83 \pm 2,401$ & $9,29 \pm 2,498$ & 0,696 \\
Setelah Pelatihan* & $12,67 \pm 2,338$ & $9,71 \pm 2,360$ & 0,045 \\
\hline
\end{tabular}

* data disajikan dalam rerata \pm simpangan baku; ${ }^{* *}$ uji beda menggunakan uji $\mathrm{T}$ tidak berpasangan dengan tingkat kemaknaan $\mathrm{p}<0,05$

beragam latar belakang pendidikan dan masa kerjanya. Tingkat pengetahuan yang baik menjadi modal utama dalam melakukan kolaborasi dengan tenaga kesehatan lainnya di puskesmas dalam rangka meningkatkan kualitas pelayanan kesehatan bagi pasien dan masyarakat.

Pengukuran pengetahuan responden dilakukan dengan memberikan pre-test sebelum kegiatan pelatihan pelayanan kefarmasian. Setelah pemberian materi, dilakukan post-test. Post-test merupakan evaluasi formatif yang diberikan pada akhir kegiatan mempunyai beberapa manfaat bagi responden, antara lain : 1) digunakan untuk mengetahui apakah responden sudah menguasai materi pelatihan, 2) merupakan penguatan (reinforcement) bagi responden, 3) usaha perbaikan sebagai umpan balik (feed back) untuk mengetahui kelemahan-kelemahan responden, dan 4) sebagai diagnosis bagi tiap responden untuk dapat mengetahui bagian mana dari materi yang masih dirasakan sulit. ${ }^{22}$

Data skor pre-test dan post-test dikumpulkan untuk kemudian dilakukan serangkaian uji statistik. Penelitian ini melakukan uji beda dengan membandingkan kelompok intervensi dan kelompok kontrol pada saat sebelum pelatihan dan setelah pelatihan untuk mengetahui tingkat pengetahuan responden pada masing-masing waktu pengujian. Uji $\mathrm{T}$ sampel tidak berpasangan dilakukan dalam penelitian ini untuk membandingkan beda rerata dari kelompok intervensi dan kontrol pada saat pre-test dan post-test. Dari tabel III menunjukkan nilai signifikansi pada saat sebelum pelatihan sebesar 0,696 ( $p>0,05)$ yang berarti bahwa tidak ada perbedaan yang nyata nilai pre-test antara kelompok intervensi dan kelompok kontrol, dengan kata lain bahwa tingkat pengetahuan responden sebelum pelatihan dari kedua kelompok penelitian tidak berbeda bermakna. Hal yang sama ditunjukkan pada penelitian yang dilakukan oleh Astuti, dkk.23 di mana hasil penelitiannya tidak menunjukkan ada perbedaan antara rerata pre-test skor pengetahuan kader pada kelompok intervensi dan kelompok kontrol. Tingkat pengetahuan yang sama dari kedua kelompok akan menjadi titik awal untuk melihat besarnya pengaruh pelatihan pada titik akhirnya.

Skor post-test dari kelompok intervensi dan kelompok kontrol juga dibandingkan menggunakan uji $\mathrm{T}$ sampel tidak berpasangan, menunjukkan nilai signifikansi sebesar 0,045 ( $p<0,05)$ yang berarti bahwa terdapat perbedaan yang nyata pada skor posttest antara kelompok intervensi dan kelompok kontrol. Perbedaan nyata ini dikarenakan adanya pengaruh pelatihan yang dilakukan pada kelompok intervensi sehingga dapat meningkatkan pengetahuan pengelola obat terhadap pelayanan kefarmasian di puskesmas. Skor pengetahuan post-test pada kelompok intervensi dan kontrol menunjukkan perbedaan yang bermakna ( $p=0,045)$ yang berarti bahwa responden pada kelompok intervensi lebih banyak menjawab dengan benar daripada responden pada kelompok kontrol disebabkan adanya pelatihan. Peningkatan pengetahuan juga dapat disebabkan oleh adanya minat peserta dan keaktifan peserta selama proses pelatihan. $^{24}$ 
Hafizh Amrullah, et al

Tabel IV. Uji Beda Skor Pengetahuan Responden berdasarkan Kelompok Penelitian

\begin{tabular}{lccc}
\hline \multicolumn{1}{c}{ Kelompok Responden } & Sebelum Pelatihan & $\begin{array}{c}\text { Setelah } \\
\text { Pelatihan }\end{array}$ & Nilai $\boldsymbol{p}^{* *}$ \\
\hline Kelompok Intervensi* $^{*}$ & $9,83 \pm 2,401$ & $12,67 \pm 2,338$ & 0,013 \\
Kelompok Kontrol $^{*}$ & $9,29 \pm 2,498$ & $9,71 \pm 2,360$ & 0,078 \\
\hline
\end{tabular}

* data disajikan dalam rerata \pm simpangan baku; ${ }^{* *}$ uji beda menggunakan uji $\mathrm{T}$ berpasangan dengan tingkat kemaknaan $\mathrm{p}<0,05$

Untuk mengetahui peningkatan pengetahuan pengelola obat di puskesmas Kabupaten Ogan Komering Ilir pada masingmasing kelompok, maka dilakukan uji beda skor kelompok intervensi pada saat sebelum pelatihan dan setelah pelatihan. Hal yang sama juga dilakukan pada kelompok kontrol. Uji beda dilakukan dengan uji $\mathrm{T}$ sampel berpasangan untuk mengetahui perbedaan rata-rata dua sampel yang saling berpasangan atau berhubungan. Hasil uji beda tersaji pada tabel IV.

Tabel IV menunjukkan bahwa pada kelompok intervensi, responden mengalami peningkatan skor pengetahuan dari 9,83 \pm 2,401 pada saat sebelum pelatihan menjadi $12,67 \pm 2,338$ pada saat setelah pelatihan. Uji T sampel berpasangan yang dilakukan pada kelompok intervensi antara skor pre-test dan post-test menunjukkan nilai $p=0,013(\mathrm{p}<0,05)$ yang berarti bahwa terdapat pengaruh pelatihan pelayanan kefarmasian dalam meningkatkan pengetahuan pengelola obat di puskesmas Kabupaten Ogan Komering Ilir. Sedangkan pada kelompok kontrol, skor pengetahan mengalami sedikit peningkatan, dari 9,29 $\pm 2,498$ pada saat pre-test menjadi 9,71 $\pm 2,360$ pada saat post-test dengan nilai signifikansi sebesar 0,078 ( $p>0,05)$.

Peningkatan signifikan skor terlihat pada kelompok intervensi dari skor pre-test sebesar 9,83 $\pm 2,401$ menjadi skor post-test $12,67 \pm 2,338 \quad(\mathrm{p}=0,013)$, menunjukkan bahwa pelatihan dapat meningkatkan pengetahuan pada aspek pengelolaan obat dan pelayanan farmasi klinik. Penambahan pengetahuan akan memperbaiki peran pengelola obat dalam melakukan pelayanan kefarmasian yang dianggap buruk oleh profesional kesehatan lainnya dan dapat meningkatkan kolaborasi antar profesional kesehatan. ${ }^{25} \mathrm{Pada}$ kelompok kontrol juga dilakukan pre-test dan post-test tanpa dilakukan pelatihan. Hasil pretest dan post-test responden pada kelompok ini hanya mengalami sedikit peningkatan skornya sebesar 9,29 $\pm 2,498$ menjadi 9,71 \pm $2,360(\mathrm{p}=0,078)$ yang berarti bahwa perbedaan rata-rata antara nilai pre-test dan post-test pada kelompok kontrol tidak berbeda bermakna. Tidak dilakukannya pelatihan pada kelompok kontrol, juga tidak mempengaruhi pengetahuan pengelola obat di puskesmas tersebut.

Gambaran skor pengetahuan pengelola obat berdasarkan aspek pengetahuan disajikan pada tabel V. Pada kelompok intervensi terjadi peningkatan skor dengan gap yang cukup tinggi pada aspek pengelolaan obat dan aspek pelayanan farmasi klinik dibandingkan kelompok kontrol. Mayoritas responden pada kelompok intervensi mengalami peningkatan skor pengetahuan pada aspek pengelolaan obat setelah dilakukan pelatihan, kecuali pengelola obat Puskesmas Sirah Pulau Padang yang mengalami penurunan skor. Hal yang sama terlihat pada aspek pelayanan farmasi klinik, di mana sebagian besar responden pada kelompok intervensi mengalami peningkatan skor setelah dilakukan pelatihan, kecuali Puskesmas Pedamaran yang memiliki skor sama dan Puskesmas Kutaraya yang mengalami penurunan skor. Skor pengetahuan responden pada kelompok kontrol sebagian besar tidak mengalami perubahan pada aspek pengelolaan obat, kecuali Puskesmas Jejawi dan Puskesmas Sugih Waras yang mengalami peningkatan 1 
Tabel V. Skor Pengetahuan Responden berdasarkan Aspek Pengetahuan

\begin{tabular}{|c|c|c|c|c|c|}
\hline \multirow{3}{*}{$\begin{array}{l}\text { Kelompok } \\
\text { Penelitian }\end{array}$} & \multirow{3}{*}{ Nama Puskesmas } & \multicolumn{4}{|c|}{ Aspek Pengetahuan yang Dinilai } \\
\hline & & \multicolumn{2}{|c|}{$\begin{array}{l}\text { Pengelolaan Obat } \\
(\text { maks. skor = 12) }\end{array}$} & \multicolumn{2}{|c|}{$\begin{array}{c}\text { Pelayanan Farmasi } \\
\text { Klinik } \\
(\text { maks. skor }=8)\end{array}$} \\
\hline & & Pre-test & Post-test & Pre-test & Post-test \\
\hline Kelompok & Puskesmas SP Padang & 6 & 5 & 4 & 6 \\
\hline \multirow[t]{6}{*}{ Intervensi } & Puskesmas Kutaraya & 6 & 8 & 5 & 4 \\
\hline & Puskesmas Pedamaran & 3 & 6 & 4 & 4 \\
\hline & Puskesmas Pedamaran Timur & 5 & 9 & 6 & 7 \\
\hline & Puskesmas Makarti Mulya & 7 & 8 & 6 & 7 \\
\hline & Puskesmas Sungai Menang & 4 & 6 & 3 & 6 \\
\hline & Rerata \pm SD & $5,17 \pm 1,47$ & $7,00 \pm 1,55$ & $4,67 \pm 1,21$ & $5,67 \pm 1,37$ \\
\hline Kelompok & Puskesmas Celikah & 5 & 5 & 4 & 4 \\
\hline \multirow[t]{7}{*}{ Kontrol } & Puskesmas Jejawi & 7 & 8 & 6 & 5 \\
\hline & Puskesmas Muara Batun & 4 & 4 & 3 & 4 \\
\hline & Puskesmas Sugih Waras & 6 & 7 & 6 & 6 \\
\hline & Puskesmas Pangarayan & 6 & 6 & 3 & 3 \\
\hline & Puskesmas Cahya Maju & 3 & 3 & 6 & 6 \\
\hline & Puskesmas P. Panggang II & 2 & 2 & 4 & 5 \\
\hline & Rerata \pm SD & $4,71 \pm 1,80$ & $5,00 \pm 2,16$ & $4,57 \pm 1,40$ & $4,71 \pm 1,11$ \\
\hline
\end{tabular}

poin pada saat post-test. Hal yang sama juga terjadi pada aspek pelayanan farmasi klinik, di mana sebagian besar skor pengetahuannya tidak mengalami perubahan, kecuali Puskesmas Muara Batun dan Puskesmas Pematang Panggang II yang mengalami peningkatan 1 poin pada saat post-test, serta Puskesmas Jejawi yang justru mengalami penurunan skor.

Pada kelompok intervensi, aspek pengelolaan obat dan pelayanan farmasi klinik mengalami peningkatan skor pengetahuan yang lebih tinggi dibandingkan kelompok kontrol. Hal ini terjadi karena adanya penambahan pengetahuan pengelola obat setelah dilakukan pelatihan. Hasil ini diharapkan dapat memenuhi harapan profesional kesehatan lainnya terhadap tenaga kefarmasian dengan memberikan lebih banyak edukasi berkaitan dengan obat dan meningkatkan teknik komunikasi antar profesional agar dapat berkomunikasi dengan lebih efektif dengan anggota tim kesehatan lainnya. ${ }^{25}$ Hasil penelitian kelompok intervensi pada aspek pengelolaan obat dan pelayanan farmasi klinik, sebagian besar responden mengalami peningkatan skor walaupun ada 1 responden yang justru mengalami penurunan skor setelah dilakukan pelatihan. Penurunan skor terjadi karena pelatihan dilakukan hanya satu hari, sehingga tidak semua responden dapat mengingat materi yang diberikan. Sedangkan pada kelompok kontrol, sebagian besar skor pengetahuan pada kedua aspek tidak mengalami perubahan, walaupun ada beberapa responden yang mengalami peningkatan skor pengetahuannya. Peningkatan skor pada kelompok kontrol disebabkan responden masih mengingat pertanyaan pada kuesioner yang diberikan pada saat pre-test, sehingga pada saat post-test dapat menjawab pertanyaan yang sama dengan benar.

Pengukuran hasil pendidikan atau pelatihan dapat dilihat salah satunya dari pengetahuan peserta terhadap materi yang diberikan (knowledge). ${ }^{26} \quad$ Pengetahuan merupakan proses yang didapatkan dari tahu dan terjadi setelah orang melakukan pengindraan dari indra penglihatan, pendengaran, penciuman, rasa, dan raba 
terhadap sebuah obyek tertentu. ${ }^{27}$ Pelatihan berupa workshop dan pemberian buku pedoman pelayanan kefarmasian dalam penelitian ini memberikan pengaruh terhadap peningkatan pengetahuan pengelola obat di puskesmas. Hasil yang sama ditunjukkan pada studi yang dilakukan Pawar dan Pawar ${ }^{20}$ bahwa pelatihan kefarmasian berpengaruh terhadap pengetahuan dan sikap farmasis yang meningkat secara signifikan. Penelitian lain juga menunjukkan bahwa terdapat hubungan bermakna antara pelatihan dan pengetahuan, di mana pengelola obat yang sering mengikuti pelatihan akan memiliki tingkat pengetahuan yang lebih baik dibandingkan dengan pengelola obat yang jarang mengikuti pelatihan. ${ }^{28}$ Penelitian Farotimi,dkk ${ }^{29}$ mengungkapkan bahwa program pelatihan terstruktur memberikan pengaruh terhadap peningkatan pengetahuan dan persepsi tenaga kesehatan secara efektif dalam pengendalian infeksi. Peningkatan pengetahuan juga dapat menambah keyakinan dan sikap dokter untuk berkolaborasi dengan tenaga kefarmasian untuk meningkatkan kepatuhan pengobatan pasien agar lebih efektif. ${ }^{30}$

Peningkatan pengetahuan pada penelitian ini dapat membentuk suatu perilaku baru dimulai dari domain kognitif, di mana responden tahu terlebih dahulu terhadap stimulus baru kemudian menimbulkan pengetahuan yang baru sehingga menimbulkan respons batin dalam bentuk sikap terhadap obyek yang diketahui tersebut dan pada akhirnya akan menimbulkan respons lebih jauh berupa tindakan (action) terhadap stimulus atau obyek tadi. ${ }^{26}$ Pada penelitian ini, output yang diinginkan adalah perubahan perilaku pengelola obat yang ada di kabupaten Ogan Komering Ilir akibat stimulus berupa pengetahuan yang didapat dari pelatihan yang dilakukan. Pengelola obat menyadari akan pentingnya praktek pelayanan kefarmasian di puskesmas sesuai standar yang ditetapkan dalam Permenkes No.74 Tahun 2016. Dari kesadaran itu dapat meningkatkan kepeduliannya terhadap tugas pokok dan fungsi (Tupoksi) sebagai pengelola obat di puskesmas, kemudian dapat mempertimbangkan baik buruknya segala tindakan yang akan dilakukan. Berikutnya pengelola obat dapat mencoba-coba beberapa inovasi berkaitan dengan pengelolaan obat dan pelayanan farmasi klinik seperti yang disampaikan pada pelatihan tersebut. Perilaku baru yang didasari pada pengetahuan dan sikap yang baik dapat berlangsung lebih lama dibandingkan dengan perilaku tanpa dasar pengetahuan dan sikap.

Intervensi pada penelitian ini menegaskan bahwa kegiatan pelatihan dapat meningkatkan pengetahuan pada aspek pengelolaan obat dan pelayanan farmasi klinik. Peningkatan pengetahuan pengelola obat ini diharapkan dapat memperbaiki kualitas pelayanan kefarmasian di puskesmas dan melindungi pasien dari penggunaan obat yang tidak rasional. Pelatihan saja tidak dapat mengarahkan ke tingkat praktek yang diinginkan, namun perlu adanya dukungan dari pihak lain untuk dapat meningkatkan kualitas pelayanan kefarmasian. Temuan ini dapat dijadikan referensi untuk pengembangan metode pelatihan yang lebih efektif di masa yang akan datang.

\section{Keterbatasan penelitian}

Meskipun pemateri pelatihan adalah tim pakar dari kalangan akademisi, durasi pelatihan tergolong cukup singkat, sehingga materi yang disampaikan merupakan materi inti berupa teori, tidak sampai pada penugasan dan praktik lapangan sesuai dengan kurikulumnya. Jarak pelaksanan pretest dan post-test pada kelompok intervensi di hari yang sama juga menjadi keterbatasan pada penelitian ini.

\section{KESIMPULAN}

Pelatihan dalam bentuk workshop selama satu hari dan pemberian buku pedoman pelayanan kefarmasian memberikan pengaruh dalam meningkatkan pengetahuan pengelola obat secara signifikan. Dengan meningkatnya pengetahuan pengelola obat diharapkan nantinya akan meningkatkan 
ketrampilan yang membentuk perilaku baru terhadap pengelolaan obat dan pelayanan farmasi klinik di puskesmas dan membantu kesiapan pengelola obat dalam berkolaborasi dengan profesional kesehatan lainnya sehingga akan menunjang peningkatan kualitas pelayanan kesehatan di seluruh puskesmas di wilayah Kabupaten Ogan Komering Ilir.

\section{UCAPAN TERIMAKASIH}

Terima kasih penulis sampaikan kepada Badan PPSDM Kementerian Kesahatan Republik Indonesia, Pemerintah Kabupaten Ogan Komering Ilir, Dinas Kesehatan Kabupaten Ogan Komering Ilir, Puskesmas Kabupaten Ogan Komering Ilir atas izin dan bantuan yang sudah diberikan dalam penelitian ini.

\section{DAFTAR PUSTAKA}

1. Mujiati M, Yuniar Y. Ketersediaan Sumber Daya Manusia Kesehatan pada Fasilitas Kesehatan Tingkat Pertama dalam Era Jaminan Kesehatan Nasional di Delapan Kabupaten-Kota di Indonesia. Media Litbangkes. 2017;26(4):201-210.

2. Aryani AF, Kusuma AM, Galistiani GF. Hubungan Tingkat Pengetahuan Pengelola Obat Terhadap Pengelolaan Obat Di Puskesmas. JMPF. 2016;6 (4)(4):303-311.

3. Srikanth M, Adepu R, S N. Impact of Educational Intervention on Knowledge, Attitude, and Practices of Urban Community Pharmacists Toward Adverse Drug Reaction Reporting in a South Indian City. Asian J Pharm Clin Res. 2016;9(2):140144.

4. Hajj A, Hallit S, Azzo C, et al., Assessment of knowledge, attitude and practice among community pharmacists towards dental care: A national cross sectional survey. Saudi Pharmaceutical Journal. 2019;27(4):475-483.

5. Alrabiah Z, Alhossan A, Alghadeer SM, Wajid S, Babelghaith SD, Al-Arifi MN. Evaluation of Community Pharmacists' Knowledge About Drug-Drug Interaction in Central Saudi Arabia. Saudi Pharmaceutical Journal. 2019;27(4):463-466.

6. Mussina AZ, Smagulova GA, Veklenko GV, et al., Effect of an Educational Intervention on the Number Potential Drug-Drug Interactions. Saudi Pharmaceutical Journal. 2019;27(5):717-723.

7. Liekens S, Vandael E, Roter D, et al., Impact of Training on Pharmacists' Counseling of Patients Starting Antidepressant Therapy. Patient Education and Counseling. 2014;94(1):110-115.

8. Sambala EZ, Sapsed S, Mkandawire ML. Role of Primary Health Care in Ensuring Access to Medicines. Croat Med J. 2010;51(3):181-190.

9. Jarab AS, AlQudah SG, Khdour M, Shamssain M, Mukattash TL. Impact of pharmaceutical care on health outcomes in patients with COPD. Int J Clin Pharm. 2012;34(1):53-62.

10. Shao $\mathrm{H}$, Chen $\mathrm{G}$, Zhu C, et al., Effect of pharmaceutical care on clinical outcomes of outpatients with type 2 diabetes mellitus. PPA. 2017;11:897-903.

11. Davis EM, Packard KA, Jackevicius CA. The Pharmacist Role in Predicting and Improving Medication Adherence in Heart Failure Patients. JMCP. 2014;20(7):741-755.

12. Shareef J, Samaga LN. Clinical Pharmacist and Pharmaceutical Care. IJPPR. 2015;3(4):160-163.

13. Altowaijri A, Phillips CJ, Fitzsimmons D. A Systematic Review of the Clinical and Economic Effectiveness of Clinical Pharmacist Intervention in Secondary Prevention of Cardiovascular Disease. JMCP. 2013;19(5):408-416.

14. Sanii Y, Torkamandi H, Gholami K, Hadavand N, Javadi MR. Role of pharmacist counseling in pharmacotherapy quality. J Res Phar Pract. 2016;5(2):132-137.

15. Yuniar Y, Herman MJ. Overcoming Shortage of Pharmacists to Provide Pharmaceutical Services in Public Health Centers in Indonesia. Kesmas: National Public Health Journal. 2013;8(1):3. 
16. Ibrahim A, Scott J. Community pharmacists in Khartoum State, Sudan: their current roles and perspectives on pharmaceutical care implementation. Int J Clin Pharm. 2013;35(2):236-243.

17. Elayeh E, Akour A, Almadaeen S, AlQhewii T, Basheti IA. Practice of pharmaceutical care in community pharmacies in Jordan. Trop J Pharm Res. 2017;16(2):463.

18. Supardi S, Susyanti AL, Herman MJ, Raharni. Evaluasi Peran Apoteker Berdasarkan Pedoman Pelayanan Kefarmasian Di Puskesmas. 2012;22 (4):190-198.

19. Hayaza YT. Analisis Kepuasan Pasien Terhadap Kualitas Pelayanan Kamar Obat di Puskesmas Surabaya Utara. Calyptra. 2013;2(2):1-13.

20. Pawar S B, Pawar A. Effect of Pharmaceutical Care Training on Knowledge Attitude and Practices of Pharmacists in Maharashtra. IJPSR. 2018;9 (10)(10):4492-4498. d

21. Kemenkes RI. Kurikulum Pelatihan Pelayanan Kefarmasian Bagi Tenaga Kefarmasian Di Puskesmas. Jakarta: Kementerian Kesehatan RI; 2019.

22. Arikunto S. Dasar-Dasar Evaluasi Pendidikan. 2nd ed. Jakarta: Bumi Aksara; 2016.

23. Astuti RT, Amin MK, Pinilih SS. Pengaruh Pelatihan Kader Terhadap Peningkatan Pengetahuan Perawatan Pada Gangguan Jiwa Di Wilayah Puskesmas Sawangan Kabupaten Magelang. Journal of Holistic
Nursing Science. 2014;1 (1)(1):13-21.

24. Wardani NI, Sr DS, Masfiah S. FaktorFaktor Yang Berhubungan Dengan Tingkat Pengetahuan Kader Kesehatan Tentang Thalassaemia Di Kecamatan Sumbang Kabupaten Banyumas. Jurnal Kesmasindo. 2014;6 (3)(3):194-206.

25. Dupotey Varela NM, Oliveira DR de, Sedeño Argilagos C, et al., What is the role of the pharmacist?: physicians' and nurses' perspectives in community and hospital settings of Santiago de Cuba. Braz J Pharm Sci. 2011;47(4):709-718.

26. Notoatmodjo S. Kesehatan Masyarakat: Ilmu Dan Seni. Jakarta: Rineka Cipta; 2011.

27. Notoatmodjo S. Promosi Kesehatan Dan Perilaku Kesehatan. Jakarta: Rineka Cipta; 2014.

28. Poernomo DH, Girsang E, Nasution SW, Ginting CN. Analisis Faktor - Faktor Yang Berhubungan Dengan Penyimpanan Obat Di Puskesmas Kota Jambi Tahun 2018. Scientia Journal. 2019;8 (1)(1):381-389.

29. Farotimi A, Ajao E, Nwozichi C, Ademuyiwa I. Effect of Training on Knowledge, Perception and Risk Reduction Regarding Infection Control Among Nurses in Selected Teaching Hospitals in Nigeria. Iranian J Nursing Midwifery Res. 2018;23 (6)(6):471-477.

30. Kucukarslan S, Lai S, Dong Y, Al-Bassam N, Kim K. Physician beliefs and attitudes toward collaboration with community pharmacists. Research in Social and Administrative Pharmacy. 2011;7(3):224232. 